\title{
Oral microbiome and peri-implant diseases: where are we now?
}

This article was published in the following Dove Press journal:

Therapeutics and Clinical Risk Management

\author{
Rafał Pokrowiecki' \\ Agnieszka Mielczarek ${ }^{2}$ \\ Tomasz Zaręba ${ }^{3}$ \\ Stefan Tyski ${ }^{3,4}$ \\ 'Department of Head and Neck \\ Surgery-Maxillofacial Surgery, \\ Otolaryngology and Ophthalmology, \\ Prof Stanislaw Popowski Voivoid \\ Children Hospital, Olsztyn, \\ ${ }^{2}$ Department of Conservative \\ Dentistry, Medical University of \\ Warsaw, ${ }^{3}$ Department of Antibiotics \\ and Microbiology, National \\ Medicines Institute, ${ }^{4}$ Department of \\ Pharmaceutical Microbiology, Medical \\ University of Warsaw, Warsaw, Poland
}

Correspondence: Rafał Pokrowiecki Department of Head and Neck SurgeryMaxillofacial Surgery, Otolaryngology and Ophthalmology, Prof Stanislaw Popowski Voivoid Children Hospital, Zołnierska I8 A, |0-56| Olsztyn, Poland

$\mathrm{Tel}+48691226414$

Fax +4889533770।

Email pokrowieckir@gmail.com

\begin{abstract}
Peri-implant infective diseases (PIIDs) in oral implantology are commonly known as peri-implant mucositis (PIM) and periimplantitis (PI). While PIM is restricted to the peri-implant mucosa and is reversible, PI also affects implant-supporting bone and, therefore, is very difficult to eradicate. PIIDs in clinical outcome may resemble gingivitis and periodontitis, as they share similar risk factors. However, recent study in the field of proteomics and other molecular studies indicate that PIIDs exhibit significant differences when compared to periodontal diseases. This review aims to elucidate the current knowledge of PIIDs, their etiopathology and diversified microbiology as well as the role of molecular studies, which may be a key to personalized diagnostic and treatment protocols of peri-implant infections in the near future.
\end{abstract}

Keywords: dental plaque, infection, titanium, microbiome, periimplantitis

\section{Introduction}

Titanium is widely used in implantation procedures in oral and maxillofacial surgery. Despite a high success rate ranging up to $98 \%$, biological complications such as periimplant mucositis (PIM) and periimplantitis (PI) are still possible threats to treatment success. ${ }^{1,2}$ PIM describes an inflammatory lesion that resides in the mucosa, while PI also affects the supporting bone. ${ }^{3,4}$ Inflammatory destruction of the implant-supporting tissues is a result of biofilm formation on the implant surface. The prevalence of periimplant infective diseases (PIIDs) was reported to be up to $80 \%$ for PIM and 56\% for PI. ${ }^{5}$ PIID in oral surgery may develop in the early postoperative period as a result of impaired wound healing (early infection), or after the process of implant integration (late infection). ${ }^{6}$

Surgical procedures in the oral cavity are classified as type 2 according to the Centers for Disease Control and Prevention guidelines. ${ }^{7}$ Hence, to minimize the risk of early infection, a prophylactic antibiotic therapy is applied. Broad-spectrum antibiotics such as penicillin or clindamycin are usually administrated in the pre- and early postoperative period in almost all fields of implant surgery in medicine. ${ }^{8,9}$ Dental implants, however, being partially external devices, are under increased risk of bacterial contamination during the whole period of the implant functioning in the oral cavity. ${ }^{10}$ Late infections represent a significant cause of dental implant failure, and they develop most commonly. This fact distinguishes oral PIIDs from other biomaterial-associated infections (BAIs). ${ }^{11}$ The latter are usually a result of surgical site infections (SSIs), which develop soon after surgery and are related to major procedures such as artificial joint implantation or the application of fracture fixation devices. As these patients are monitored postoperatively in the hospital, SSIs can be easily detected and treated with simple wound drainage and antibiotic administration. ${ }^{12}$ Once an implant - such as an 
internal fixator or endoprosthesis - is healed, it is unlikely to develop infection as it is retained beneath the protecting barrier of tissues such as the skin, muscles and fascia. ${ }^{10} \mathrm{By}$ contrast, an implant is exposed in the oral cavity throughout its functioning time. Therefore, the risk of bacterial contamination of the peri-implant area is constant, as bacterial plaque is forming steadily on the implant's surface. Hygiene measures are for now the only weapon against biofilm formation. Unfortunately, it frequently poses a challenge for the clinicians to detect the infection before irreversible damage occurs around the implant. Moreover, subjective symptoms of the patient may differ. That is why some patients only seek help when advanced infection is already established. Because current possibilities in disease detection are still not explicated, implication for new diagnostic tools is required.

\section{Biofilm formation on oral implants and disease development}

Bacterial adhesion to an abiotic surface is a complex physicochemical phenomenon, which was first described as the "race for the surface" by Gristina et al. ${ }^{13,14}$ It describes the process where the surface poses a substratum on which host and bacterial cells compete. If bacteria inhabit the surface in sufficient numbers, the implant will become infected and in some cases require removal. ${ }^{15}$ This model of infection development proposed by Gristina et al was a benchmark for technological and material studies in the field of regenerative medicine for many years. However, the composition of the bacterial biofilm responsible for infections of orthopedic devices is not as diversified as the dental plaque which forms in the oral cavity. Biofilms formed around orthopedic fixators are mainly composed of Staphylococci and/or Streptococci and are infrequently followed by Escherichia coli or Pseudomonas aeruginosa. ${ }^{12}$ Bacterial colonies in oral infections are characterized by manifold and multispecies composition. ${ }^{16,17}$

The process of formation of oral bacterial biofilm, which is responsible for periodontal disease, was thoroughly evaluated by Teles et al, ${ }^{18}$ Haffajee and Socransky ${ }^{19}$ and Quirynen et $\mathrm{al}^{20}$ at Forsyth Dental Center. These researchers assumed that the tooth surface is consecutively colonized by different, subsequently appearing complexes of bacteria in the following order: yellow/purple $\rightarrow$ orange $\rightarrow$ red/green. Moreover, the clinical symptoms of infection usually reflect the amount and composition of dental plaque harbored around the tooth. This pattern of bacterial settlement was also translated into a model of oral implant infections, as it was assumed that PIIDs shared common features with periodontal diseases. With time, despite some similarities, it became obvious that they do in fact differ in many ways. ${ }^{21,22}$ PIID is a result of concomitant factors associated with the general status of the patient, the quality and quantity of the surrounding tissues and the characteristics of the implant material. Uncontrolled diabetes mellitus, autoimmune disorders, genetic factors, bisphosphonate therapy, head and neck radiotherapy, chemotherapy, smoking and alcohol consumption are the most commonly listed general risk factors for infection. ${ }^{23,24}$ Chronic systemic diseases, chemotherapy, surgical trauma or bacterial contamination during implant surgery are considered risk factors associated with early implant failures. These result in impaired healing of the surgically wounded tissues. ${ }^{25-27}$ Antibiotic prophylaxis, as well as preoperative mouth rinse with $0.2 \%$ chlorhexidine, can reduce the incidence of early failures. ${ }^{28,29}$ Local factors such as dental calculus, improper dental fillings, and failed endodontic treatment of neighboring teeth increase the risk of implant infection, and hence these issues must be resolved prior to any surgical procedure in the oral cavity. ${ }^{30-32}$

Dental implant susceptibility to infection is also caused by the morphology of peri-implant tissues. Healing after implant insertion consists of osseo- and periointegration. These two independent but highly related phenomena are a result of host's response to foreign material being placed into the jawbones. ${ }^{33}$ Osseointegration describes the biological connection of the living bone with the intraosseous screws. ${ }^{34}$ It is completed within 3-6 months after implant placement into the dental alveolus. At the genetic level, osseointegration appears to be a result of inflammation decrease in favor of osteo-, angio- and neurogenesis at the early stages of wound healing. ${ }^{33}$ Periointegration describes the formation of peri-implant mucosa around the transmucosal abutment, which usually takes place within 8-12 weeks after abutment insertion. ${ }^{35,36}$ Nevertheless, even when properly healed, periimplant tissues differ significantly from periodontal tissues surrounding natural teeth. ${ }^{35}$ The latter constitute a collar seal formed by alveolar bone, periodontal ligament and a cementum called periodontium which separates teeth from the environment of the oral cavity. While those structures develop during tooth eruption, peri-implant tissues form as a result of surgical trauma during wound repair. ${ }^{36,37}$ These fundamental differences in tissue morphogenesis implicate further distinct features of peri-implant tissue morphology. ${ }^{22,38}$ These include the following: a lack of periodontal space, the scar tissue nature of soft tissues, receded blood flow caused by poor vascularity and a deeper sulcus which allows for deeper penetration of bacteria..$^{39,40}$ Thus, even a fully integrated dental implant exhibits a space which is more susceptible to bacterial infection than periodontal tissues. 
The process of biofilm formation on implant surface is comparable to biofilm formation on natural teeth. Surface characteristics of the colonized material may influence the amount and composition of biofilm formation, as with the enamel of natural teeth. ${ }^{41,42}$ Nevertheless, the role of surface properties on biofilm formation is still being investigated. Rough surfaces may accumulate more supra- and subgingival dental plaques than smooth ones. ${ }^{41}$ This is due to deeper plaque retention in irregular surface niches where bacteria are protected from the natural cleansing effect of saliva, cheeks and tongue movements and oral hygiene measures. ${ }^{3,43}$ Bacterial colonization patterns are also related to factors other than just the value of the mean surface roughness. ${ }^{44}$ The aspect of surface wettability is regarded as the second most relevant factor in the dynamics of cell adhesion to the surface. ${ }^{45,46}$ Some researchers described hydrophobic surfaces as accumulating more bacterial plaque than hydrophilic ones. ${ }^{47,48}$ The explanation for this phenomenon has usually referred to the simplified principles of thermodynamics based on adhesion forces calculated with the DLVO (Derjaguin and Landau, Verwey and Overbeek) theory. ${ }^{49}$ As most species of oral bacteria possess cell walls of a hydrophobic nature, they will easily adhere to the similar surfaces. Analogously, bacteria with hydrophilic cell walls will adhere to surfaces of hydrophilic nature. However, the large heterogeneity of the phylotypes of the microbial population in the oral cavity as well as their ability to switch from hydrophobic to hydrophilic in response to environmental changes should be taken into consideration. ${ }^{50,51}$ In clinical conditions, bacteria attach to implant surfaces through a protein medium called acquired pellicle (AP) composed of proteins and sugars derived from saliva. Formation of AP prior to bacterial adhesion is crucial for subsequent biofilm formation. Pellicle covers all surfaces in the oral cavity regardless of their wettability or roughness. ${ }^{52}$ Hence, it constitutes an isolating medium that triggers an initial attachment of the bacterial species through trans-membranous proteins, commonly known as adhesins. ${ }^{53,54} \mathrm{AP}$ is an intermediate conditioning film separating the implant surface from oral bacteria. Therefore, it may also have an impact on implant surface properties obtained during implant manufacturing. Moreover, in biological fluid, the presence of salts and proteins may regulate the interactions between hydrophilic and hydrophobic surfaces. ${ }^{50}$ The mechanisms and forces governing AP formation prior to biofilm settlement are still under evaluation.

Some authors suggest that material type and its purity should also be taken into consideration as titanium and zirconium may exhibit different patterns of bacterial biofilm formation. ${ }^{44}$ No differences, however, were found in AP protein composition or its bacterial binding properties between them. ${ }^{55}$ Therefore, the current data are still too inaccurate to draw any conclusions as to which of these materials is more prone to bacterial adhesion. Consequently, the forces responsible for microbial adhesion to implant surfaces in the oral cavity are still not fully understood. Disparities between the available data make it challenging to draw conclusions concerning the role of surface wettability in biofilm formation around oral implants in the clinical environment. ${ }^{56}$ None of in vitro and in vivo studies have found a practical exploitation in the field of antibacterial and anti-adhesive surfaces application in oral implantology so far. Therefore, the problem of biofilm formation around dental implants is still pending, regardless of the shape, macro- and microfeatures or surface modification. ${ }^{23}$

Bacterial colonization of the surface irregularities starts around 30 minutes after the implant is introduced into the environment of the oral cavity. ${ }^{20,57}$ Initial adhesion begins at locations where bacteria are sheltered from shear forces. ${ }^{49,58}$ Initial attachment of bacteria is driven by hydrophobic, electrostatic and van der Waals forces which bring the cells closer to the implant surface coated by AP. After bacteria directly adhere to the AP's proteins, an irreversible attachment is established. From this moment on, bacterial metabolic activity is upregulated, and migration spreads out on the implant surface. As dental plaque maturates, the diversity of the microbial community increases. ${ }^{14,59,60}$ Recent studies with a high throughput of sequencing technologies identified more than 700 bacterial species and 25,000 phylotypes in the oral cavity. ${ }^{16,17,61,62}$ The precise definition of the oral microbiome is still difficult. ${ }^{63}$ Nonetheless, a major proportion of bacterial sequences obtained from patients in different studies seem to be comparable. This indicates that there might be specific "core microbiota," which are different in "healthy" and "diseased" mouths. ${ }^{16,17,61}$ Pathological conditions, such as untreated periodontal disease or other concomitant factors, may, however, induce changes in the oral ecosystem which favor the colonization of the implant sites. During the early phase of biofilm formation, supra- and subgingival dental plaque is dominated mostly by Grampositive cocci, nonmotile bacilli and a limited number of Gram-negative anaerobic species..$^{27,38} \mathrm{~A}$ healthy peri-implant socket is mainly colonized by oral Streptococci which constitute from $45 \%$ to $86 \%$ of supra- and subgingival peri-implant sulcus microbiota. Actinomyces naeslundii, Actinomyces oris and Actinomyces meyeri, as well as Neisseria and Rothia species, are also frequently isolated. ${ }^{20,64,65}$ In the study by 
Diaz et al, ${ }^{66}$ early colonizers were as follows: Streptococcus thermophilus, Streptococcus oralis, Streptococcus infantis and Streptococcus sanguinis species followed by Neisseria pharyngis and Gemella haemolysans. These bacteria were considered by the authors to be a core group, providing the basis for the subsequent colonization of facultative and obligate anaerobes. Moreover, subject-specific shifts in biofilm composition of the Streptococci species between the 4 th and 8 th hour of biofilm formation were observed. ${ }^{66}$ In the study by Maruyama et al, ${ }^{16}$ early colonizers correlated positively with each other and initiated colonization of the orange complex bacteria. On the other hand, negative correlations between early and late colonizers were also observed. A decrease in the Streptococcus intermedius level was followed by an increase in Eubacterium nodatum species at infected sites.

In another study, Thurnheer and Belibasakis ${ }^{67}$ aimed to develop a "submucosal" in vitro biofilm model by integration of Staphylococcus aureus and Staphylococcus epidermidis into its composition and, hence, shift patterns between these species. Authors proved that when S. epidermidis was coinoculated with $S$. aureus, the former failed to grow in the biofilm partially explaining the more frequent detection of S. aureus in sites with PI. ${ }^{67}$ What is more interesting is that this is not common for other BAIs.

Shift patterns depend on specific interrelationships between bacterial species. The formation of dental plaque is a dynamic process which may result in significant shifts during the very first hours after implant exposure to the oral cavity. ${ }^{68}$ According to some studies, however, there is a compelling discrepancy in the quality and quantity of peri-implant microbiota between the tested populations. It was observed that even healthy peri-implant sulcus may be infrequently colonized by periodontopathogenic Fusobacterium nucleatum, Prevotella intermedia, Porphyromonas gingivalis and Aggregatibacter actinomycetemcomitans. These pathogens were identified in healthy peri-implant pockets without any symptoms of inflammation. ${ }^{69,70}$ On that account, it seems that peri-implant infections are not a straightforward consequence of the presence of periodontopathogenic species per se. They are instead, highly related to the host's response to composition shifts of subject-specific oral microbiota. Consequently, potential periodontopathogenic species may not be invasive as long as their proportion is below the critical level. On the other hand, they can pose a potential risk for infection once the symbiotic balance between the host and the microbiota is lost. It may be possible that the interindividual variation in microflora of the digestive tract, including the oral cavity, can be attributed to differences in host factors that modulate colonization patterns. ${ }^{58}$ This may partly explain a clinical observation in cases where inflammation severity does not correspond with oral hygiene measures. As an example, there are patients who suffer from PIIDs despite having a proper hygiene regimen and vice versa - there are cases with no clinical signs of infection despite poor oral hygiene or a history of "periodontitis" or smoking. PIID appears to result from an inappropriate inflammatory reaction to the normal microbiota exacerbated by the presence of some disease-associated bacterial species, host-related factors, geographical factors influencing disease progression and the characteristics of the foreign body material. ${ }^{61,63}$ These interactions are elucidated in Figure 1.

Nonetheless, to better understand the complex interactions between host's response and microbial biofilm, more studies and new models are required. ${ }^{23,68}$ In the work by Hajishengallis and Lamont, ${ }^{71}$ the polymicrobial synergy and dysbiosis model of periodontal disease development was proposed. According to the current state of the art, PIIDs in oral implantology may also develop in this way. These, however, are additionally influenced by the presence of the material and physicochemical phenomena at implant-tissue interface. Figure 2 represents a proposed model of the mechanisms involved in peri-implant infections.

\section{PIM and PI}

A several-week period of uninterrupted plaque maturation may lead to a shift in bacterial biofilm composition. When this is accompanied by the immune system disintegration of the host, peri-implant mucosa inflammation may be established. This is described as PIM, which is regarded as important transitional event in the progression to PI. ${ }^{3,78} \mathrm{~A}$ shift from healthy peri-implant sulcus to a diseased peri-implant pocket is associated with the increased presence of cocci, motile bacilli and spirochetes. A change in biofilm distribution is commonly more prominent in subgingival rather than supragingival dental plaque. ${ }^{79-81}$ Therefore, PIM may result in an increase in the proportion of periodontopathogenic bacteria, mostly from the orange complex: F. nucleatum, $P$. intermedia and Eubacterium species. A decrease in Streptococci spp. and Actinomyces spp. is also common. ${ }^{82,83}$ Clinically, PIM may be identified by redness and swelling of the soft tissues. Bleeding on probing (BOP), however, is currently recognized as the most important feature above all other symptoms of infections. Pain is an unusual symptom. Yet, if present, it is generally associated with acute infection. ${ }^{80,84}$ Histopathological examination reveals an inflammatory lesion in the connective tissue of the peri-implant mucosa 


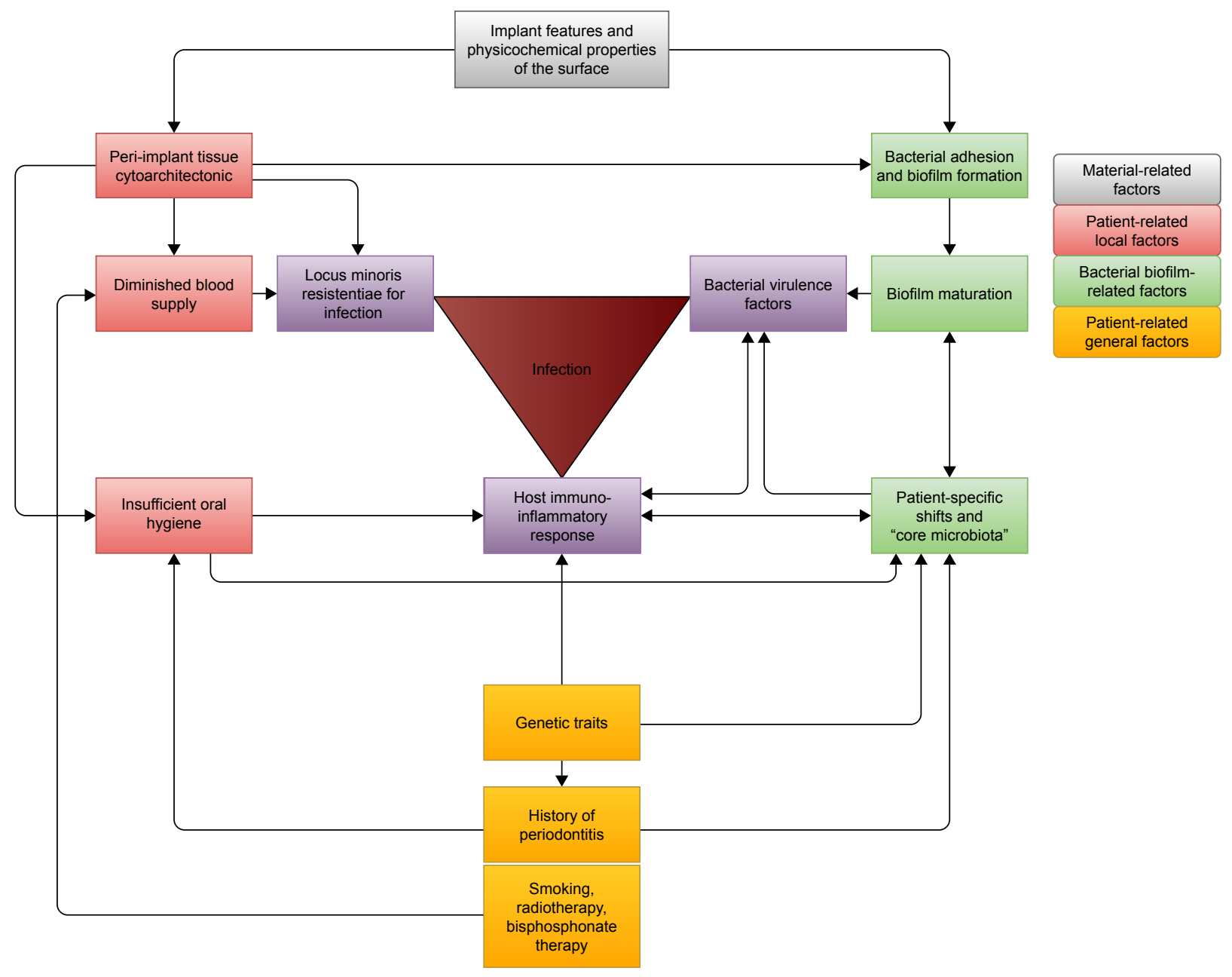

Figure I Peri-implant infection is a result of the co-occurrence of several, highly related factors.

Notes: Implant characteristics influence both: peri-implant tissue cytoarchitectonics which is highly susceptible to bacterial infiltration and constitutes locus minoris resistentiae [a place of less resistance] for bacterial infiltration. On the other hand, the implant surface poses a favorable niche for bacterial adhesion and biofilm maturation. Smoking decreases blood flow in peri-implant capillaries leading to a higher risk of infection. Insufficient hygiene measures and a history of "periodontitis" are important risk factors for the development of PIIDs. Genetic traits may be responsible for host immunoinflammatory response and subject-specific shifts in the oral biofilm. When the three major components exist simultaneously, an infection development at the implant-tissue interface has a high possibility.

Abbreviation: PIID, peri-implant infective disease.

dominated by plasma cells and lymphocytes. ${ }^{85}$ There is no sign of bone loss on clinical and radiographic examination. Supramucosal plaque formation should be considered as the main initial event in the development of PI. ${ }^{3}$ PIM, however, is reversible if proper oral hygiene accompanied by nonsurgical treatment of the infected screw is performed. ${ }^{86}$

Persistent inflammation may spread further, reach deeper parts of the peri-implant area and result in the development of PI. The process is described as inflammatory, affecting tissues around an osseointegrated implant in function, resulting in loss of supporting bone. ${ }^{3}$ In PI, a subject-specific shift in subgingival biofilm may be present as well. These are usually associated with an increase in the level of pathogenic bacteria from the orange and red complexes. $P$. gingivalis and Tannerella forsythia are the most common and abundant red complex species, whereas Prevotella nigrescens, Prevotella oris and $F$. nucleatum are frequently isolated periodontal pathogens from the orange complex..$^{26,69}$ Bacterial species associated with PI may, however, significantly differ from those involved in periodontal disease. Species isolated from infected peri-implant pockets, yet infrequently abundant in infected periodontal sites, were Synergistetes spp. HOT360, Pseudoramibacter alactolyticus, Eubacterium spp., Veillonella spp., Enterobacteriaceae, Candida spp., Filifactor alocis, Dialister invisus and Mitsuokella spp. HOT 131, Peptococcus spp. HOT-168, Clostridiales [F-1][G-1] spp. HOT093, Catonella morbid, Chloroflexi spp. and Tenericutes spp. ${ }^{21,87,88}$ Porphyromonas spp. HOT-395, P. nigrescens and P. oris were proposed as part of the "core microbiome" in PI by Maruyama et al. ${ }^{16}$ Therefore, the microflora of infected 


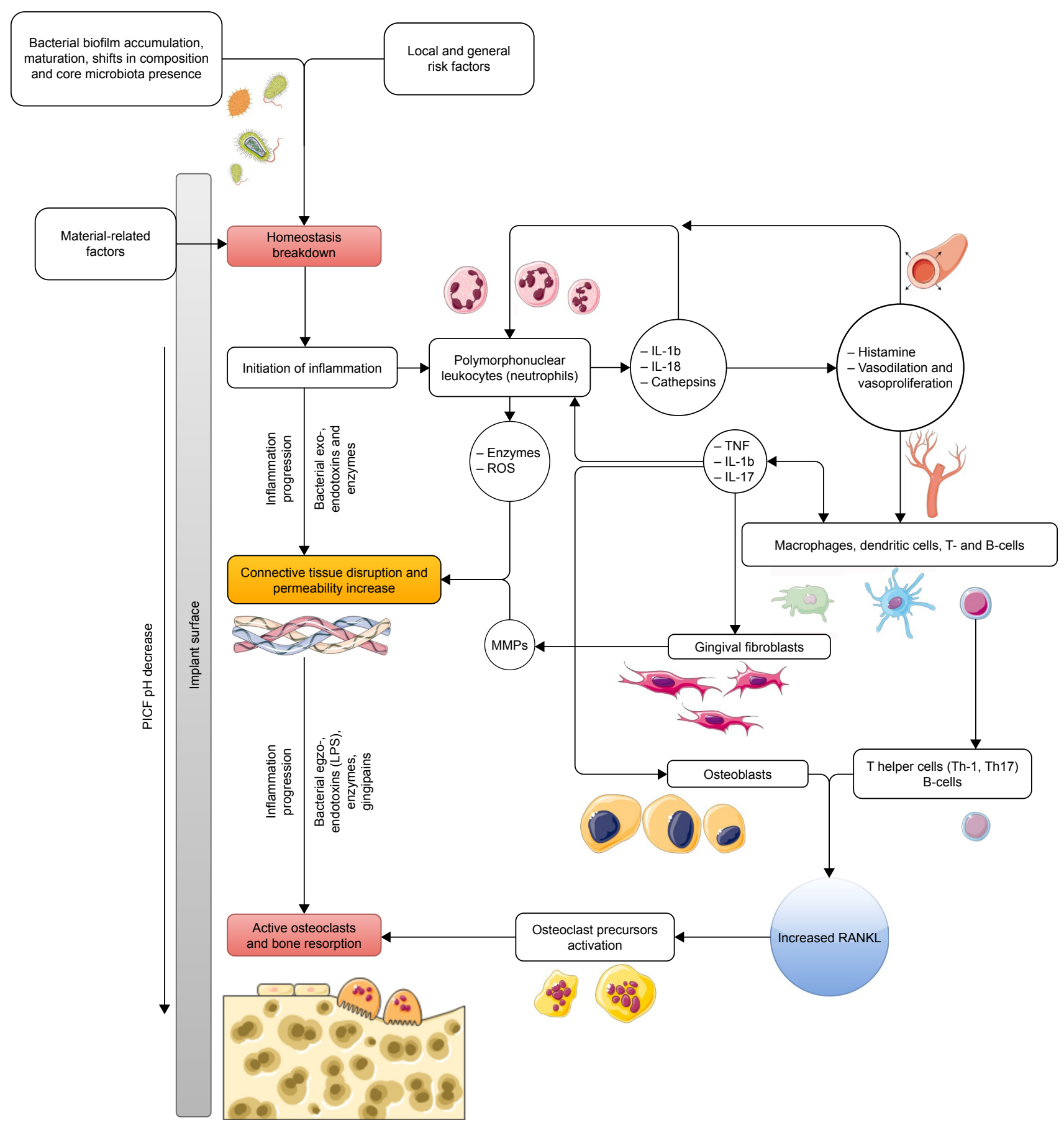

Figure 2 The modified PSD model of peri-implant disease is based on the work by Hajishengallis and Lamont ${ }^{71}$ and Hajishengallis. ${ }^{72}$

Notes: Interactions between bacterial- and host-related factors lead to homeostasis breakdown, similar to the PSD model. ${ }^{73}$ In this case, however, material-related factors (roughness, wettability and chemical composition) also play a substantial role. Bacterial products in the peri-implant sulcus act as a chemotactic stimulus for PMN migration through connective tissues. This early stage of inflammation is associated with microvascular changes (vasodilation) - in the peri-implant epithelium and pro-inflammatory cytokine release (IL-Ib, IL-8a and cathepsins). Vasodilation and vasoproliferation increase the PMN infiltrate, cytokine release and recruitment of other immune cell types (macrophages, dendritic cells, T- and B-cells). Soft tissues around rough implant surfaces are characterized by greater microvessel density and a higher number of T- and B-cell infiltrate when compared to tissues around smooth implant surfaces. ${ }^{74}$ Peri-implant mucosa may also present less Langerhans cells and more interstitial cells. ${ }^{75}$ Release of TNF, IL- 17 and IL exacerbates the inflammatory response by stimulation of PMNs to produce enzymes, ROS and fibroblasts to release MMPs. In the presence of bacterial exotoxins and enzymes, connective tissue disruption occurs, leading to increased tissue permeability and fibroblast degeneration. The proliferation of epithelium into collagen-depleted areas results in pocket deepening, infection progression and a pH decrease in PICF. ${ }^{76} \mathrm{TNF}$, IL-Ib and IL-I7 also regulate the development of T helper cells which lead to the expression of the osteoblast RANKL and initiate the maturation of osteoclast precursors. This process is also facilitated by PMNs if they are within sufficient proximity to the bone. Gram-negative bacterial virulence factors (especially LPS and gingipains) exacerbate the inflammatory process and bone resorption. Decreased pH of the PICF or mechanical injury of the implant surface may initiate $\mathrm{TiO}_{2}$ layer dissolution and corrosion process. ${ }^{76} \mathrm{The}$ ions/metallic particles of titanium may be phagocytosed by macrophages. This results in an additional release of pro-inflammatory cytokines (mainly IL-8b) when macrophages are coexposed to LPS.77

Abbreviations: LPS, lipopolysaccharides; MMP, metalloproteinase; PICF, peri-implant crevicular fluid; PMN, polymorphonuclear leukocyte; PSD, polymicrobial synergy and dysbiosis; RANKL, receptor activator of the nuclear factor kappa B ligand; ROS, reactive oxygen species. 
peri-implant sites is found to be much more diverse than in periodontitis. ${ }^{83,89,90}$ Staphylococcus spp. are characteristic for BAIs as these species have a high affinity to titanium surfaces. ${ }^{59}$ Established inflammation decreases the $\mathrm{pH}$ value of the peri-implant environment. Microbial-mediated corrosion is responsible for the thinning of the $\mathrm{TiO}_{2}$ protective layer of an implant body. ${ }^{76}$ Titanium wear products induce cytotoxicity and hence escalate the inflammation process by cytokine production and bone osteolysis. ${ }^{77}$

Bacterial shifts in peri-implant microbiota are not a common phenomenon. Until now, few comprehensive studies comparing the microbiota of healthy and infected periimplant sites were conducted. ${ }^{69}$ The study by Perrson and Renvert (2014) on 213 subjects with a total of 976 implants in use showed no statistically significant differences in the microbiota on healthy and diseased implants. ${ }^{69}$ On the other hand, Cortelli et $\mathrm{al}^{87}$ described higher bacterial frequency in PI and PIM in comparison to healthy peri-implant sites. However, a progressive increase in the frequency was not observed for all tested species. The authors concluded that implants may exhibit specific bacterial microbiota that is not totally similar to the bacteria of diseased teeth. ${ }^{87}$ In addition, the composition of the bacterial pattern was not related to the patient's dental status or smoking habits. A contribution of other noncultivable pathogens could be involved in the disease process. A. actinomycetemcomitans, $P$. gingivalis, $P$. intermedia, $T$. forsythia and Treponema denticola may be present at both healthy and diseased peri-implant sites and, therefore, are not strictly related to peri-implant disease sites. ${ }^{91}$ By contrast, Al-Radha et $\mathrm{al}^{92}$ demonstrated that periodontal pathogens including $P$. gingivalis, $T$. forsythia, A actinomycetemcomitans, P. intermedia and Fusobacterium spp. were found at about $40 \%$ of infected peri-implant sites. In the study by Persson and Renvert, ${ }^{69}$ infected peri-implant sites harbored amounts of T. forsythia, P. gingivalis, Tannerella socransky, S. aureus, Staphylococcus anaerobius, S. intermedius and Streptococcus mitis approximately four times higher than that found on healthy implants. ${ }^{67}$ These species constituted $30 \%$ of peri-implant microbiota at infected sites and $14.1 \%$ at healthy sites. ${ }^{69} P$. gingivalis, $T$. denticola and $T$. forsythia exist as a consortium that exhibits synergistic virulence resulting in immunoinflammatory bone resorption. ${ }^{93}$ In the recent study by Tsigarida et al, ${ }^{78}$ it was proven that bacterial shifts in core microbiome are different in smokers and nonsmokers. Authors showed that smoking may shape peri-implant microbiome in states of clinical health, depleting commensals and enriching for pathogenic species. These observations are in contrary to the aforementioned observations of Cortelli et al. ${ }^{87}$
Moreover, Apatzidou et $\mathrm{al}^{94}$ recently proved that diseased peri-implant sites and healthy periodontal tissues in the same individuals with the history of periodontitis represent distinct microbiological ecosystems.

A significant discrepancy between results confirms, however, that PIIDs are an intra-individual, polymicrobial infection where certain core microbiota may pose a significant role. In addition, subject-related shifts may depend on the interactions between bacteria as well as the interaction with the host immune response. In the absence of a metaanalysis, variability in microbiologic outcomes and the limited number of available studies make the current evidence for straightforward microbiological analysis of peri-implant sites currently unachievable. ${ }^{63}$

\section{Clinical and radiological symptoms of PIIDs}

A healthy dental implant can be described as nonmobile, with no radiographic evidence of peri-implant translucency and absence of pain and pathology. A maximum of $1 \mathrm{~mm}$ of bone loss in 1 year following implant loading and $0.02-0.15 \mathrm{~mm}$ annually thereafter is acceptable. There is a functional survival rate of $90 \%$ for 5 years, and $85 \%$ for 10 years, and an esthetically acceptable outcome is also expected. ${ }^{34,95}$ An implant that has not fulfilled the predefined success criteria but is stable is regarded as "failing." An implant that has lost its integrity with the bony tissue requires removal. ${ }^{84,96,97}$

Implant failure may be a result of both mechanical and/ or biological complications, where peri-implant infections represent the latter. ${ }^{98,99}$ Modern dentistry regards implant treatment as a continuous process, where regular checkup visits are an absolute requirement for therapeutic success. Consequently, potential infection control should be performed conscientiously. To evaluate the condition of the periimplant area, clinical examination of marginal tissues should be performed in the first place. ${ }^{100}$ In periodontal disease, the first sign of inflammation is gingival redness and swelling. However, a subjective assessment of peri-implant soft tissue condition may be insufficient, as it exhibits some distinct features. For example, a soft tissue collar around the dental implant abutment is commonly nonkeratinized mucosa. This is usually redder than keratinized gingiva present around the natural teeth. ${ }^{101,102}$ Moreover, the color and characteristics of the transmucosal implant abutment may exert an effect on the surrounding tissues. ${ }^{84}$ Thus, an assessment of the peri-implant mucosa should be performed by gentle manual examination of peri-implant sulcus with a blunt, calibrated 
periodontal probe. ${ }^{103}$ Angulation of the probe at $\sim 60^{\circ}$ of the long axis of the tooth/implant and running it along the gingival margin enables an objective soft tissue assessment. The pressure force of the probe should not exceed $0.25 \mathrm{~N}$ as peri-implant probing depth measurements are more sensitive to force variation than periodontal pocket probing. ${ }^{3,104}$ This examination enables the detection of two main parameters of the peri-implant condition: BOP and peri-implant pocket depth (PPD). ${ }^{105} \mathrm{BOP}$ is an essential, early sign of underlying inflammation, which is considered a major indicator of peri-implant infection. It is a result of micro-ulcerations in the epithelium that lines the peri-implant pocket and may be present even without visible signs of infection. ${ }^{4}$ Lack of BOP correlates with healthy pockets in $98.8 \%$ of cases. By contrast, its presence is diagnosed in $67 \%-90 \%$ of cases of PIM, and more than $97 \%$ of cases of PI. ${ }^{25,103,106}$ Increased pocket depth (PD) and clinical attachment loss (CAL) are pathognomonic for periodontal diseases (Table 1). ${ }^{3,84}$ These parameters are, however, a matter of debate as far as dental implants are concerned. It has been shown that PD of a healthy implant may vary as well. Its values are related to the type of the implant system used, depth and angulation of the intraosseous screw in the jawbone, type of implant-abutment connection, abutment emergence profile, biotype of the peri-implant soft tissues as well as the implant's surface roughness. A disparity of soft tissue composition, organization and attachment of the gingiva make the conditions for PD measurements around teeth and implants not fully comparable. ${ }^{84,105}$ In esthetic zone, an implant is inserted deeper into the bone to avoid its potential exposure by gingival recession. When it occurs, a part of gray implant is visible while smiling. Deeper submerging prevents this scenario from happening. ${ }^{107}$ Pus discharge from the peri-implant socket is a definitive symptom of an ongoing infection. ${ }^{103}$ Suppuration may be attributed to either severe PIM or PI. Hence, a proper diagnostic protocol must be supplemented by a radiographic examination. Diversified criteria for radiological symptoms of PI were proposed by different authors. In general, it is argued that the following symptoms may indicate PI: progressive marginal bone loss of $>0.2 \mathrm{~mm}$ annually, or $>3$ threads of intraosseous screw, or $>2-3 \mathrm{~mm}$ from implant-abutment connection covered by bone are exposed into the oral cavity due to bone resorption (Table 1). ${ }^{103,108}$ The differential diagnosis of PIM and PI must always be supplemented with radiographic examination. ${ }^{109}$ It should be emphasized that bone loss facilitated by infection must be separated from mechanical overload of the implant. ${ }^{98}$ Persistent, infiltrating inflammation may result in progressive resorption of the circumferential bone and produce implant mobility.

\section{Human markers of PIID}

A shift from healthy peri-implant sulcus into the infected periimplant pocket is induced by bacterial pathogenic activity. The inflammatory response of the host's tissues is mediated by bacterial virulence factors responsible for pro-inflammatory cytokine release, as well as enzyme and toxin production. These soluble mediators of immune reactions present in the peri-implant crevicular fluid (PICF) are produced as a result of the physiological interaction of gingival epithelium and local leukocytes with dental plaque and oral microorganisms, regardless of the type of implant-abutment connection. ${ }^{110-113} \mathrm{~A}$ proteomic approach to periodontal and peri-implant diseases has recently been viewed as a helpful tool in proper diagnostic and therapeutic protocol of these infectious diseases. ${ }^{114-116}$ The contents of PICF may reflect the status of a peri-implant sulcus, either healthy or diseased (Table 2).

Recently, a few human protein biomarkers restricted to periodontal health have been described (Table 2): clusterins (related to the removal of cellular debris and apoptosis), angiotensinogen, thymidine phosphorylase (maintains the integrity of the blood vessels), ${ }^{117,118}$ calprotectin (wound healing and cell proliferation), adrenomedullin (antimicrobial through trace metal

Table I Clinical and radiological parameters of healthy and infected peri-implant tissues

\begin{tabular}{|c|c|c|c|c|}
\hline Peri-implant tissue & Clinical parameters & References & Radiological parameters & References \\
\hline \multirow[t]{2}{*}{ Healthy pocket } & $\mathrm{BOP}(-)$ & 3,82 & Up to $0.15 \mathrm{~mm}$ annually after loading & 99,104 \\
\hline & PD 3-5 mm & & & \\
\hline \multirow[t]{3}{*}{ PIM } & $\mathrm{BOP}(+)$ & & Up to $0.15 \mathrm{~mm}$ annually after loading & \\
\hline & $\mathrm{PD}>5 \mathrm{~mm}( \pm)$ & & & \\
\hline & Suppuration $( \pm)$ & & & \\
\hline \multirow[t]{4}{*}{ PI } & $\mathrm{BOP}(+)$ & & $0.2 \mathrm{~mm}$ annually after loading, $>2 \mathrm{~mm}$ in & \\
\hline & Increased PD (+) & & general or $>3$ implant threads exposed & \\
\hline & Suppuration $(+)$ & & & \\
\hline & Mobility $( \pm)$ & & & \\
\hline
\end{tabular}

Abbreviations: BOP, bleeding on probing; PD, pocket depth; PI, periimplantitis; PIM, peri-implant mucositis. 
Table 2 Human biomarkers of healthy and infected peri-implant tissues

\begin{tabular}{|c|c|c|}
\hline Peri-implant tissue & Markers & References \\
\hline \multirow[t]{3}{*}{ Healthy pocket } & Clusterin, angiotensinogen & 112,113 \\
\hline & $\beta$-defensin family, cathelicidin (LL-37), calprotectin, adrenomedullin & 114 \\
\hline & Thymidine phosphorylase & 115 \\
\hline \multirow{6}{*}{ PIM - mild inflammation } & Proinflammatory cytokines: & \\
\hline & $\uparrow$ IL-I $\beta$, TNF- $\alpha$, MIP-I $\alpha$, IL-8, IL-6, ICTP, MMP-I, cathepsins & $108,110,116$ \\
\hline & Proteins associated with connective tissue destruction: & \\
\hline & $\uparrow$ keratins, titin, actin- and microtubule-associated proteins, I-plastin, histone $\mathrm{H} 4, \mathrm{HI} .2$ & 110,116 \\
\hline & Apolipoprotein & 120 \\
\hline & Others: $\uparrow \mathrm{tPA}, \mathrm{PAI}-2$ & 130 \\
\hline \multirow[t]{8}{*}{ PI - severe inflammation } & Pro-inflammatory cytokines: & \\
\hline & $\uparrow$ IL-I $\beta$, TNF- $\alpha$, MIP-I $\alpha$, IL-8, IL-6, Ig-GI, PGE-2, MMP-8 & 121,124 \\
\hline & Proteins associated with bone tissue destruction: & \\
\hline & $\uparrow$ cathepsin G, osteopontin, osteonectin, osteocalcin calprotectin, ALP, ICTP & 110,113 \\
\hline & $\uparrow$ RANKL, $\downarrow$ OPG & 106,112 \\
\hline & Others: & \\
\hline & $\downarrow$ tPA, PAI-2 & 130 \\
\hline & $\uparrow$ Neutrophil-derived defensin-I,carbonic anhydrase-I, elongation factor I-gamma & 113 \\
\hline
\end{tabular}

Notes: $\uparrow$ represents increase; $\downarrow$ represents decrease.

Abbreviations: ALP, alkaline phosphatase; OPG, osteoprotegerin; PAI-2, plasminogen activator inhibitor 2; PI, periimplantitis; PIM, peri-implant mucositis; RANKL, receptor activator of the nuclear factor kappa $B$ ligand; tPA, tissue plasminogen activator.

ion binding), human $\beta$-defensins (immune cell chemotaxis), cathelicidin (LL-37) ${ }^{119}$ and thymidine phosphorylase. ${ }^{120}$

The early stage of inflammation is characterized by an increase in human pro-inflammatory cytokines and chemokines. After the transition from a healthy to a diseased pocket, IL- $1 \beta$, TNF- $\alpha$, MIP- $1 \alpha$, IL- 8 and MMPs may be detected in the PICF. ${ }^{115,121}$ Although a significant relationship between the concentration of those cytokines and the severity of the inflammatory response has been described, this is not a common phenomenon. ${ }^{113,122,123}$

It means that the presence of pro-inflammatory cytokines may help to detect infection but provides insufficient evidence to distinguish between PIM and PI. ${ }^{124}$ Over time, the inflammatory phase increases and facilitates connective tissue disruption. Several human biomarkers related to connective tissue breakdown detected in PICF have been described (Table 2): C-telopeptide pyridinoline cross-links (ICTP), as well as cytoskeletal-associated proteins (keratins, titin and actin- and microtubule-associated proteins) whose numerical increase in PICF indicates the higher turnover of epithelium, which may correspond with ongoing inflammation. ${ }^{115,121}$ In addition, proteoglycans and fibronectin fragments may be detectable as the counterparts of damaged soft tissues. ${ }^{121} \mathrm{An}$ increased level of apolipoprotein B-100 reflects the presence of micro-ulcerations in sulcular epithelium and indicates the early stage of inflammation. ${ }^{125}$ Therefore, the presence of specific proteins associated with soft tissue destruction detected in PICF may indicate inflammation restricted to peri-implant mucosa.
Persistent inflammation eventually leads to bone resorption, and hence to increased mobility of the infected implant. Of all pro-inflammatory cytokines, MMP- 8 is regarded as the main collagenase involved in severe PI. ${ }^{126-128}$ Some studies also indicated that the level of IL- 6 and PGE-2 was increasing along with PPD. PGE-2 is a known mediator for bone resorption by the mechanisms of vasodilation, increase in vascular permeability and activation of osteoclasts. ${ }^{126,129}$ The promising markers for bone resorption are also OPG, receptor activator of the nuclear factor kappa B (RANK) and receptor activator of the nuclear factor kappa $B$ ligand (RANKL). ${ }^{11,130}$ Pro-inflammatory mediators induce osteoclastogenesis by promotion of RANK expression and OPG suppression. RANKL, also known as the osteoclast differentiation factor, binds directly to RANK. This complex activates pre-osteoclasts and osteoclasts to both differentiation of progenitory cells and mature activity. As an increase in the RANK level in PICF is undoubtedly connected with increased bone turnover and may indicate active inflammation, the significance of OPG-level fluctuations is still controversial. ${ }^{131-133}$ It is also worth remembering that elevated OPG and RANKL are strictly connected with bone turnover after osteotomy preparation in the early postoperative period. ${ }^{134}$

Other biomarkers associated with increased bone turnover, which may indicate bone resorption, are osteocalcin, osteopontin, bone collagen fragments, alkaline phosphatase (ALP), cathepsin and pyridinoline cross-linked carboxyterminal telopeptide of type I collagen (ICTP). ${ }^{115}$ Baliban et al ${ }^{118}$ described a few additional proteins which were restricted 
to chronic periodontitis, and hence could also be helpful in diagnosing PI: neutrophil-derived defensin-1, carbonic anhydrase-1 and elongation factor 1-gamma. Recently, Hall et $\mathrm{a}^{135}$ argued that the plasminogen system and inflammation could be used to distinguish mucositis from PI. The upregulation of tissue plasminogen activator (tPA) - plasminogen activator inhibitor 2 (PAI-2) - was observed in PIM. The downregulation of the plasminogen system accompanied by an increased level of pro-inflammatory cytokines was, however, a strong predictor for PI. ${ }^{135}$ Other studies also confirm the potential applicability of proteomic approach in defining the status of peri-implant tissues. ${ }^{118,120,123,124}$

\section{Bacterial markers of peri-implant disease}

A transition from healthy peri-implant sulcus into the PIM and PI may find its reflection in specific bacterial proteins (Table 3).

Several markers of commensal microbiota associated with gingival health have been described: chaperonin, iron uptake A2 protein and phosphoenolpyruvate carboxylase. ${ }^{118,120}$ Markers for chronic periodontitis, which may also play a substantial role in PI, are ribulose biphosphate carboxylase, succinyl-CoA:3-ketoacid-coenzyme A transferase and DNA-directed RNA polymerase subunit beta. ${ }^{118}$ The maturation of the biofilm and an increase in the number of pathogenic bacteria enable the detection of cell wall proteins associated with certain species. F. nucleatum is mostly responsible for aggregation with human lymphocytes, invasion of epithelial cells and coaggregation with other putative species. It may contribute to peri-implant disease

Table 3 Bacterial biomarkers of healthy and infected peri-implant tissues

\begin{tabular}{|c|c|c|}
\hline $\begin{array}{l}\text { Peri-implant } \\
\text { tissue }\end{array}$ & Markers & References \\
\hline Healthy pocket & $\begin{array}{l}\uparrow \text { Chaperonin, iron uptake A2 } \\
\text { protein, phosphoenolpyruvate } \\
\text { carboxylase }\end{array}$ & 113 \\
\hline PIM & $\begin{array}{l}\text { AdpB (Prevotella spp.) } \\
\text { FadA (Fusobacterium spp.) }\end{array}$ & $131,133,134$ \\
\hline PI & $\begin{array}{l}\text { Ribulose biphosphate carboxylase, } \\
\text { succinyl-CoA:3-ketoacid-coenzyme } \\
\text { A transferase, DNA-directed RNA } \\
\text { polymerase subunit beta }\end{array}$ & 113 \\
\hline & RgpA, RgpB, P59, P27 (P. gingivalis) & $115,135-137$ \\
\hline & Dentilisin, MsP (Treponema sp.) & $138,140,144$ \\
\hline & Karylisin, prtH, bspA (Tannerella spp.) & $142-144$ \\
\hline
\end{tabular}

Note: $\uparrow$ represents increase.

Abbreviations: P. gingivalis, Porphyromonas gingivalis; PI, periimplantitis; PIM, periimplant mucositis. development by invading oral mucosa and inducing local inflammation and increased expression of cytokines. FadA adhesin is considered to be involved in tissue cell attachment and invasion. Therefore, this protein constitutes the main virulence factor of orally related fusobacteria ${ }^{136-138}$ Another distinctive surface protein with broad-spectrum extracellular matrix binding abilities is AdpB found in Prevotella spp. ${ }^{139}$ $P$. intermedia, $P$. nigrescens, $T$. forsythia and $P$. gingivalis demonstrate the ability of immunoglobulin (IgA, IgG, IgM) degradation. This process involves lysine-specific cysteine proteases, which is also described as gingipains. These have been recently evaluated in $P$. gingivalis $\mathrm{RgpA}, \mathrm{RgpB}, \mathrm{P} 59$ and P27 strains and were classified as the main virulence factors of Porphyromonas spp. ${ }^{140-143}$

Virulence factors of $T$. denticola identified so far were Msp, cfpA and dentilysin. Msp mediates adhesion to other bacteria and host components and, as a porin, acts as a permeable pore, and it contributes to antibiotic resistance. Dentilysin exerts cytotoxic effects on host epithelial cells and induces the local deregulation of cytokines, which may cause long-lasting infections. ${ }^{14-146}$ It also binds to gingipains and hence plays an essential role in synergistic polymicrobial biofilm formation with $P$. gingivalis. ${ }^{147} \mathrm{CfpA}$ is also required for establishing a mixed biofilm with $P$. gingivalis. ${ }^{145}$ Virulence factors found in $T$. forsythia and described so far are karilysin, prtH and bspA. PrtH is a cysteine protease which causes the detachment of adherent cultured cells and is an expression of the pro-inflammatory cytokine IL-8. Karilysin is a metalloprotease that cleaves and inactivates several components of complement system. BspA induces alveolar bone loss, promotes invasion of the epithelial cells and induces the production of IL- 8 cytokines. ${ }^{148-150}$

\section{Conclusion}

Both natural teeth and dental implant surfaces harbor a bacterial biofilm in the oral cavity. A pattern of early colonization and maturation of the dental plaque is facilitated by multiple factors. Material-related factors are accompanied by periimplant tissue morphology and structure which facilitate susceptibility to infections. An incredibly diversified composition of subject-related oral microbiomes makes it difficult to fully understand the relationships between the bacteria living in the dental plaque biofilm. Therefore, in the view of the presented data, PIIDs do not seem to be infectious diseases in the classical sense because they result from a complex interaction in which the host's susceptibility plays a major role. Although microbial diversity and richness varies, recent studies have indicated that there might be a common core of microbiota with a characteristic structure in health and 
disease. A transition from healthy peri-implant sulcus into an inflamed peri-implant pocket is related to subject-specific bacterial shifts in dental plaque. These may also be related to the patient's general status, environmental and geographical factors, diet and smoking. PIM and PI are nonspecific, polymicrobial and heterogeneous diseases of an endogenous nature. They are also more difficult to diagnose and treat than periodontal diseases. The vast majority of clinical studies dealing with dental implant infections are being monitored by means of parameters used in the periodontal examination of natural teeth, which seem to be insufficient in the case of PIIDs. The diversity of peri-implant tissues and the, as yet, not fully understood phenomena at the bacteria-surfacetissue interface imply the need for new, reliable, more sensitive and reproducible diagnostic protocols that combine clinical, radiological, microbiological and molecular studies. It seems that monitoring the specific biomarkers in the PICF could be a helpful tool in the early detection of the disease (eg, increase in apolipoprotein-100, IL-8), monitoring the ongoing infection (eg, increased level of pro-inflammatory cytokines) or its progression (eg, increased level of cytokines followed by the markers of bone resorption and specific "red complex" markers) as well as the resolution phase (eg, decrease in pro-inflammatory cytokines and ICTP, increase in neutrophil defensins). Beyond any doubt, the unification and standardization of diagnostic protocols is still required to reduce the incidence rate of BAIs which are still the second most common cause of implant loss. The enhancement of diagnostic protocols, a better understanding of the epidemiology of PIIDs, risk management and personalized patient care are still needed. ${ }^{78}$

\section{Disclosure}

The authors report no conflicts of interest in this work.

\section{References}

1. Zhuang LF, Watt RM, Mattheos N, Si MS, Lai HC, Lang NP. Periodontal and peri-implant microbiota in patients with healthy and inflamed periodontal and peri-implant tissues. Clin Oral Implants Res. 2016; 27(1):13-21.

2. Zitzmann NU, Berglundh T; Group D of European Workshop on Periodontology. Definition and prevalence of peri-implant diseases. $J$ Clin Periodontol. 2008;35(suppl 8):286-291.

3. Lindhe J, Meyle J; Group D of European Workshop on Periodontology. Peri-implant diseases: consensus report of the Sixth European Workshop on Periodontology. J Clin Periodontol. 2008;35(suppl 8):282-285.

4. Lang NP, Wilson TG, Corbet EF. Biological complications with dental implants: their prevention, diagnosis and treatment. Clin Oral Implant Res. 2000;11(suppl 1):146-155.

5. Romanos GE, Weitz D. Therapy of peri-implant diseases. Where is the evidence? J Evid Based Dent Pract. 2012;12(3 suppl):204-208.

6. Jakobi M, Stumpp S, Stiesch M, Eberhard J, Heuer W. The peri-implant and periodontal microbiota in patients with and without clinical signs of inflammation. Dent J. 2015;3(2):24-42.
7. Mangram AJ, Horan TC, Pearson ML, Silver LC, Jarvis WR. Guideline for prevention of surgical site infection, 1999. Centers for Disease Control and Prevention (CDC) Hospital Infection Control Practices Advisory Committee. Am J Infect Control. 1999;27(2):97-132.

8. Cutando-Soriano A, Galindo-Moreno P. Antibiotic prophylaxis in dental patients with body prostheses. Med Oral. 2002;7(5):348-359.

9. Diefenbeck M, Mückley T, Hofmann GO. Prophylaxis and treatment of implant-related infections by local application of antibiotics. Injury. 2006;37(2):S95-S104.

10. Campoccia D, Montanaro L, Arciola CR. A review of the clinical implications of anti-infective biomaterials and infection-resistant surfaces. Biomaterials. 2013;34(33):8018-8029.

11. Arciola CR, Campoccia D, Ehrlich GD, Montanaro L. Biofilm-based implant infections in orthopaedics. Adv Exp Med Biol. 2015;830: 29-46.

12. Trampuz A, Zimmerli W. Diagnosis and treatment of infections associated with fracture-fixation devices. Injury. 2006;37(2):S59-S66.

13. Gristina AG, Naylor PT, Webb LX. Molecular mechanisms in musculoskeletal sepsis: the race for the surface. Instr Course Lect. 1990; 39:471-482.

14. Gristina AG, Naylor P, Myrvik Q. Infections from biomaterials and implants: a race for the surface. Med Prog Technol. 1988;14(3-4): 205-224.

15. Gallo J, Holinka M, Moucha CS. Antibacterial surface treatment for orthopaedic implants. Int J Mol Sci. 2014;15:13849-13880.

16. Maruyama N, Maruyama F, Takeuchi Y, Aikawa C, Izumi Y, Nakagawa I. Intraindividual variation in core microbiota in peri-implantitis and periodontitis. Sci Rep. 2014;4:6602.

17. Griffen AL, Beall CJ, Firestone ND, et al. CORE: a phylogeneticallycurated $16 \mathrm{~S}$ rDNA database of the core oral microbiome. PLoS One. 2011;6(4):1-10.

18. Teles RP, Haffajee AD, Socransky SS. Microbiological goals of periodontal therapy. Periodontol 2000. 2006;42(1):180-218.

19. Haffajee AD, Socransky SS. Relationship of cigarette smoking to the subgingival microbiota. J Clin Periodontol. 2001;28(5):377-388.

20. Quirynen M, Vogels R, Pauwels M, et al. Initial subgingival colonization of "pristine" pockets. J Dent Res. 2005;84(4):340-344.

21. Dabdoub SM, Tsigarida AA, Kumar PS. Patient-specific analysis of periodontal and peri-implant microbiomes. J Dent Res. 2013; 92(12 suppl):168S-175S.

22. Becker ST, Beck-Broichsitter BE, Graetz C, Dörfer CE, Wiltfang J, Häsler R. Peri-implantitis versus periodontitis: functional differences indicated by transcriptome profiling. Clin Implant Dent Relat Res. 2014; 16(3):401-411.

23. Renvert S, Polyzois I. Risk indicators for peri-implant mucositis: a systematic literature review. J Clin Periodontol. 2015;42(16):S172-S186.

24. Ihde S, Kopp S, Maier T. Comparison of implant survival with implants placed in acceptable and compromised bone: a literature review. J Maxillofac Oral Surg. 2009;8(1):1-7.

25. Zitzmann NU, Berglundh T. Definition and prevalence of peri-implant diseases. J Clin Periodontol. 2008;35(8 suppl):286-291.

26. Quirynen M, De Soete M, van Steenberghe D. Infectious risks for oral implants: a review of the literature. Clin Oral Implants Res. 2002; 13(1):1-19.

27. Pye AD, Lockhart DEA, Dawson MP, Murray CA, Smith AJ. A review of dental implants and infection. J Hosp Infect. 2009;72(2):104-110.

28. Friedlander AH, Hazboun RC. Antibiotics and implants. J Am Dent Assoc. 2015;146(3):146.

29. Keenan JR, Veitz-Keenan A. Antibiotic prophylaxis for dental implant placement? Evid Based Dent. 2015;16(2):52-53.

30. Liddelow G, Klineberg I. Patient-related risk factors for implant therapy. A critique of pertinent literature. Aust Dent J. 2011;56(4):417-426.

31. Zhou W, Han C, Li D, Li Y, Song Y, Zhao Y. Endodontic treatment of teeth induces retrograde peri-implantitis. Clin Oral Implants Res. 2009;20(12):1326-1332.

32. Martinez A, Guitián F, López-Píriz R, et al. Bone loss at implant with titanium abutments coated by soda lime glass containing silver nanoparticles: a histological study in the dog. PLoS One. 2014;9(1):e86926. 
33. Salvi GE, Bosshardt DD, Lang NP, et al. Temporal sequence of hard and soft tissue healing around titanium dental implants. Periodontol 2000. 2015;68(1):135-152.

34. Albrektsson T, Brånemark PI, Hansson HA, Lindström J. Osseointegrated titanium implants. Requirements for ensuring a long-lasting, direct boneto-implant anchorage in man. Acta Orthop Scand. 1981;52(2):155-170.

35. Tomasi C, Tessarolo F, Caola I, Wennström J, Nollo G, Berglundh T. Morphogenesis of peri-implant mucosa revisited: an experimental study in humans. Clin Oral Implants Res. 2014;25(9):997-1003.

36. Sculean A, Gruber R, Bosshardt DD. Soft tissue wound healing around teeth and dental implants. J Clin Periodontol. 2014;41(suppl 15):S6-S22.

37. Yamaza T, Kido MA. Biological Sealing and Defense Mechanisms in Peri-Implant Mucosa of Dental Implants. London: INTECH Open Access Publisher; 2011. Available from: https://www.intechopen.com/ books/implant-dentistry-the-most-promising-discipline-of-dentistry/ biological-sealing-and-defense-mechanisms-in-peri-implant-mucosaof-dental-implants. Accessed October 20, 2017.

38. Belibasakis GN. Microbiological and immuno-pathological aspects of peri-implant diseases. Arch Oral Biol. 2014;59(1):66-72.

39. Villar CC, Huynh-Ba G, Mills MP, Cochran DL. Wound healing around dental implants. Endod Top. 2011;25(1):44-62.

40. Li J, Chen J, Kirsner R. Pathophysiology of acute wound healing. Clin Dermatol. 2007;25(1):9-18.

41. Teughels W, Assche N, Sliepen I, Quirynen M. Effect of material characteristics and/or surface topography on biofilm development. Clin Oral Implants Res. 2006;17(suppl 2):68-81.

42. Rosan B, Lamont RJ. Dental plaque formation. Microbes Infect. 2000; 2(13):1599-1607.

43. Cavalcanti YW, Soare RV, Leite Assis MA, Zenóbio EG, Girundi FM. Titanium surface roughing treatments contribute to higher interaction with salivary proteins MG2 and lactoferrin. J Contemp Dent Pract. 2015;16(2):141-146.

44. Violant D, Galofré M, Nart J, Teles RP. In vitro evaluation of a multispecies oral biofilm on different implant surfaces. Biomed Mater. 2014;9(3):35007.

45. Thevenot P, Hu W, Tang L. Surface chemistry influences implant biocompatibility. Curr Top Med Chem. 2008;8(4):270-280.

46. RuppF, Scheideler L, Eichler M, Geis-Gerstorfer J. Wetting behavior of dental implants. Int J Oral Maxillofac Implants. 2011;26(6):1256-1266.

47. Yamada Y, Yamada M, Ueda T, Sakurai K. Reduction of biofilm formation on titanium surface with ultraviolet-C pre-irradiation. $J$ Biomater Appl. 2014;29(2):161-171.

48. Thewes N, Loskill P, Jung P, et al. Hydrophobic interaction governs unspecific adhesion of staphylococci: a single cell force spectroscopy study. Beilstein J Nanotechnol. 2014;5:1501-1512.

49. Boks NP, Norde W, van der Mei HC, Busscher HJ. Forces involved in bacterial adhesion to hydrophilic and hydrophobic surfaces. Microbiology. 2008;154(10):3122-3133.

50. Krasowska A, Sigler K. How microorganisms use hydrophobicity and what does this mean for human needs? Front Cell Infect Microbiol. 2014;4:112.

51. Gallardo-Moreno AM, Navarro-Pérez ML, Vadillo-Rodríguez V, Bruque JM, González-Martín ML. Insights into bacterial contact angles: difficulties in defining hydrophobicity and surface Gibbs energy. Colloids Surf B Biointerfaces. 2011;88(1):373-380.

52. Gibbins HL, Yakubov GE, Proctor GB, Wilson S, Carpenter GH. What interactions drive the salivary mucosal pellicle formation? Colloids Surf B Biointerfaces. 2014;120:184-192.

53. Zijnge V, Van Leeuwen MBM, Degener JE, et al. Oral biofilm architecture on natural teeth. PLoS One. 2010;5(2):1-9.

54. Heo S-M, Ruhl S, Scannapieco FA. Implications of salivary protein binding to commensal and pathogenic bacteria. J Oral Biosci. 2013; 55(4):169-174.

55. Lima EMCX, Koo H, Vacca Smith AM, Rosalen PL, Del Bel Cury AA. Adsorption of salivary and serum proteins, and bacterial adherence on titanium and zirconia ceramic surfaces. Clin Oral Implants Res. 2008; 19(8):780-785.
56. Gittens RA, Scheideler L, Rupp F, et al. A review on the wettability of dental implant surfaces II: biological and clinical aspects. Acta Biomater. 2014;10(7):2907-2918.

57. van Winkelhoff AJ, Goene RJ, Benschop C, Folmer T. Early colonization of dental implants by putative periodontal pathogens in partially edentulous patients. Clin Oral Implant Res. 2000;11(6):511-520.

58. Charalampakis G, Belibasakis GN. Microbiome of peri-implant infections: lessons from conventional, molecular and metagenomic analyses. Virulence. 2015;6(3):183-187.

59. Costerton JW, Montanaro L, Arciola CR. Biofilm in implant infections: its production and regulation. Int J Artif Organs. 2005;28(11):1062-1068.

60. Al-Ahmad A, Wiedmann-Al-Ahmad M, Fackler A, et al. In vivo study of the initial bacterial adhesion on different implant materials. Arch Oral Biol. 2013;58(9):1139-1147.

61. Costalonga M, Herzberg MC. The oral microbiome and the immunobiology of periodontal disease and caries. Immunol Lett. 2014;162(2): $22-38$.

62. Zaura E, Keijser BJF, Huse SM, Crielaard W. Defining the healthy "core microbiome" of oral microbial communities. BMC Microbiol. 2009;9(1):259.

63. Wade WG. The oral microbiome in health and disease. Pharmacol Res. 2013;69(1):137-143.

64. Elter C, Heuer W, Demling A, et al. Supra- and subgingival biofilm formation on implant abutments with different surface characteristics. Int J Oral Maxillofac Implants. 2008;23(2):327-334.

65. Quiryen M, Gijbels F, Jacobs R. An infected jawbone site compromising successful osseointegration. Periodontol. 2000;2003(33):129-144.

66. Diaz PI, Chalmers NI, Rickard AH, et al. Molecular characterization of subject-specific oral microflora during initial colonization of enamel. Appl Environ Microbiol. 2006;72(4):2837-2848.

67. Thurnheer T, Belibasakis GN. Incorporation of staphylococci into titanium-grown biofilms: an in vitro "submucosal" biofilm model for peri-implantitis. Clin Oral Implants Res. 2016;27(7):890-895.

68. Peyyala R, Ebersole JL. Multispecies biofilms and host responses: "discriminating the trees from the forest". Cytokine. 2013;61(1):15-25.

69. Persson GR, Renvert S. Cluster of bacteria associated with periimplantitis. Clin Implant Dent Relat Res. 2014;16(6):783-793.

70. Casado PL, Otazu IB, Balduino A, de Mello W, Barboza EP, Duarte MEL. Identification of periodontal pathogens in healthy periimplant sites. Implant Dent. 2011;20(3):226-235.

71. Hajishengallis G, Lamont RJ. Beyond the red complex and into more complexity: the polymicrobial synergy and dysbiosis (PSD) model of periodontal disease etiology. Mol Oral Microbiol. 2012;27(6): 409-419.

72. Hajishengallis G. Immunomicrobial pathogenesis of periodontitis: keystones, pathobionts, and host response. Trends Immunol. 2014; 35(1):3-11.

73. Hajishengallis G, Lamont RJ. Breaking bad: manipulation of the host response by Porphyromonas gingivalis. Eur J Immunol. 2014;44(2): $328-338$

74. Degidi M, Artese L, Piattelli A, et al. Histological and immunohistochemical evaluation of the peri-implant soft tissues around machined and acid-etched titanium healing abutments: a prospective randomised study. Clin Oral Investig. 2012;16(3):857-866.

75. Horewicz VV, Ramalho L, dos Santos JN, Ferrucio E, Cury PR. Comparison of the distribution of dendritic cells in peri-implant mucosa and healthy gingiva. Int J Oral Maxillofac Implants. 2013;28(1):97-102.

76. Pozhitkov AE, Daubert D, Brochwicz Donimirski A, et al. Interruption of electrical conductivity of titanium dental implants suggests a path towards elimination of corrosion. PLoS One. 2015;10(10):e0140393.

77. Pettersson M, Kelk P, Belibasakis GN, Bylund D, Molin Thorén M, Johansson A. Titanium ions form particles that activate and execute interleukin- $1 \beta$ release from lipopolysaccharide-primed macrophages. J Periodontal Res. 2017;52(1):21-32.

78. Tsigarida AA, Dabdoub SM, Nagaraja HN, Kumar PS. The influence of smoking on the peri-implant microbiome. J Dent Res. 2015;94(9): 1202-1217. 
79. Derks J, Tomasi C. Peri-implant health and disease. A systematic review of current epidemiology. J Clin Periodontol. 2015;42(S16): S158-S171.

80. Sanz M, Chapple IL; Working Group 4 of the VIII European Workshop on Periodontology. Clinical research on peri-implant diseases: consensus report of Working Group 4. J Clin Periodontol. 2012;39: 202-206

81. Shibli JA, Melo L, Ferrari DS, Figueiredo LC, Faveri M, Feres M. Composition of supra- and subgingival biofilm of subjects with healthy and diseased implants. Clin Oral Implants Res. 2008;19(10): 975-982.

82. Faveri M, Figueiredo LC, Shibli JA, Pérez-Chaparro PJ, Feres M. Microbiological diversity of peri-implantitis biofilms. Adv Exp Med Biol. 2015;830:85-96.

83. Koyanagi T, Sakamoto M, Takeuchi Y, Ohkuma M, Izumi Y. Analysis of microbiota associated with peri-implantitis using 16S rRNA gene clone library. J Oral Microbiol. 2010;2(2010):1-7.

84. Chen S, Darby I. Dental implants: maintenance, care and treatment of peri-implant infection. Aust Dent J. 2003;48(4):212-263.

85. Berglundh T, Zitzmann NU, Donati M. Are peri-implantitis lesions different from periodontitis lesions? J Clin Periodontol. 2011; 38(suppl 11):188-202.

86. Jepsen S, Berglundh T, Genco R, et al. Primary prevention of periimplantitis: managing peri-implant mucositis. J Clin Periodontol. 2015;42:S152-S157.

87. Cortelli SC, Cortelli JR, Romeiro RL, et al. Frequency of periodontal pathogens in equivalent peri-implant and periodontal clinical statuses. Arch Oral Biol. 2013;58(1):67-74.

88. da Silva ESC, Feres M, Figueiredo LC, Shibli JA, Ramiro FS, Faveri M. Microbiological diversity of peri-implantitis biofilm by Sanger sequencing. Clin Oral Implants Res. 2014;25(10):1192-1199.

89. Koyanagi T, Sakamoto M, Takeuchi Y, Maruyama N, Ohkuma M, Izumi Y. Comprehensive microbiological findings in peri-implantitis and periodontitis. J Clin Periodontol. 2013;40(3):218-226.

90. Lafaurie GI, Sabogal MA, Castillo DM, et al. Microbiome and microbial biofilm profiles of peri-implantitis: a systematic review. J Periodontol. 2017;88(10):1066-1089.

91. Renvert S, Roos-Jansåker AM, Lindahl C, Renvert H, Rutger Persson G. Infection at titanium implants with or without a clinical diagnosis of inflammation. Clin Oral Implants Res. 2007;18(4):509-516.

92. Al-Radha ASD, Pal A, Pettemerides AP, Jenkinson HF. Molecular analysis of microbiota associated with peri-implant diseases. J Dent. 2012;40(11):989-998.

93. Kesavalu L, Sathishkumar S, Bakthavatchalu V, et al. Rat model of polymicrobial infection, immunity, and alveolar bone resorption in periodontal disease. Infect Immun. 2007;75(4):1704-1712.

94. Apatzidou D, Lappin DF, Hamilton G, Papadopoulos CA, Konstantinidis A, Riggio MP. Microbiome associated with periimplantitis versus periodontal health in individuals with a history of periodontal disease. J Oral Microbiol ISSN J. 2017;83:145-152.

95. Roos J, Sennerby L, Lekholm U, Jemt T, Gröndahl K, Albrektsson T. A qualitative and quantitative method for evaluating implant success: a 5-year retrospective analysis of the Brånemark implant. Int J Oral Maxillofac Implants. 1997;12(4):504-514.

96. Moraschini V, Poubel LA, Ferreira VF, Barboza Edos SP. Evaluation of survival and success rates of dental implants reported in longitudinal studies with a follow-up period of at least 10 years: a systematic review. Int J Oral Maxillofac Surg. 2015;44(3):377-388.

97. Romanos G, Ko H-H, Froum S, Tarnow D. The use of CO(2) laser in the treatment of peri-implantitis. Photomed Laser Surg. 2009;27(3): 381-386

98. Esposito M, Hirsch JM, Lekholm U, Thomsen P. Biological factors contributing to failures of osseointegrated oral implants. (I). Success criteria and epidemiology. Eur J Oral Sci. 1998;106(1):527-551.

99. Sakka S, Baroudi K, Nassani MZ, et al. Factors associated with early and late failure of dental implants. Cochrane Database Syst Rev. 2012; 3(9):Cd004970.
100. Tonetti MS, Chapple ILC, Jepsen S, Sanz M. Primary and secondary prevention of periodontal and peri-implant diseases: introduction to, and objectives of the 11th European Workshop on Periodontology consensus conference. J Clin Periodontol. 2015;42(S16):S1-S4.

101. Charalampakis G, Rabe P, Leonhardt Å, Dahlén G. A follow-up study of peri-implantitis cases after treatment. J Clin Periodontol. 2011; 38(9):864-871.

102. Greenstein G, Cavallaro J. The clinical significance of keratinized gingiva around dental implants. Compend Contin Educ Dent. 2011; 32(8):24-31.

103. Heitz-Mayfield LJA. Peri-implant diseases: diagnosis and risk indicators. J Clin Periodontol. 2008;35(suppl 8):292-304.

104. Heitz-Mayfield L, Mombelli A. The therapy of peri-implantitis: a systematic review. Int J Oral Maxillofac Implants. 2014;29(suppl):325-345.

105. Salvi GE, Lang NP. Diagnostic parameters for monitoring periimplant conditions. Int J Oral Maxillofac Implants. 2004;19(suppl): 116-127.

106. Roos-Jansaker A-M, Lindahl C, Renvert H, Renvert S. Nine- to fourteen-year follow-up of implant treatment. Part II: presence of peri-implant lesions. J Clin Periodontol. 2006;33(4):290-295.

107. Nguyen-Hieu T, Borghetti A, Aboudharam G. Peri-implantitis: from diagnosis to therapeutics. J Investig Clin Dent. 2012;3(2):79-94.

108. Tomasi C, Derks J. Clinical research of peri-implant diseases - quality of reporting, case definitions and methods to study incidence, prevalence and risk factors of peri-implant diseases. J Clin Periodontol. 2012;39(supp112):207-223.

109. Atieh MA, Alsabeeha NHM, Faggion CM, Duncan WJ. The frequency of peri-implant diseases: a systematic review and meta-analysis. J Periodontol. 2012;84(11):1-15.

110. Öztürk VÖ, Emingil G, Bostanci N, Belibasakis GN. Impact of implant-abutment connection on osteoimmunological and microbiological parameters in short implants: a randomized controlled clinical trial. Clin Oral Implants Res. 2017;28(9):e111-e120.

111. Emecen-Huja P, Hasan I, Miller CS. Biologic markers of failing implants. Dent Clin North Am. 2015;59(1):179-194.

112. Javed F, Al-Hezaimi K, Salameh Z, Almas K, Romanos GE. Proinflammatory cytokines in the crevicular fluid of patients with periimplantitis. Cytokine. 2011;53(1):8-12.

113. Petković AB, Matić SM, Stamatović NV, et al. Proinflammatory cytokines (IL-1beta and TNF-alpha) and chemokines (IL-8 and MIP-1alpha) as markers of peri-implant tissue condition. Int J Oral Maxillofac Surg. 2010;39(5):478-485.

114. Ramseier CA, Eick S, Brönnimann C, Buser D, Brägger U, Salvi GE Host-derived biomarkers at teeth and implants in partially edentulous patients. A 10-year retrospective study. Clin Oral Implants Res. 2016;27(2):211-217.

115. Zia A, Khan S, Bey A, Gupta ND, Mukhtar-Un-Nisar S. Oral biomarkers in the diagnosis and progression of periodontal diseases. Biol Med. 2011;3(2 special issue):45-52.

116. Slotte $\mathrm{C}$, Lennerås $\mathrm{M}$, Göthberg C, et al. Gene expression of inflammation and bone healing in peri-implant crevicular fluid after placement and loading of dental implants. A kinetic clinical pilot study using quantitative real-time PCR. Clin Implant Dent Relat Res. 2012; 14(5):723-736.

117. Rosa N, Correia MJ, Arrais JP, Costa N, Oliveira JL, Barros M. The landscape of protein biomarkers proposed for periodontal disease: markers with functional meaning. Biomed Res Int. 2014;2014:569632.

118. Baliban RC, Sakellari D, Li Z, DiMaggio PA, Garcia BA, Floudas CA Novel protein identification methods for biomarker discovery via a proteomic analysis of periodontally healthy and diseased gingival crevicular fluid samples. J Clin Periodontol. 2012;39(3):203-212.

119. Hans M, Madaan Hans V. Epithelial antimicrobial peptides: guardian of the oral cavity. Int J Pept. 2014;2014:370297.

120. Baliban R, Sakellari D, Li Z, DiMaggio PA, Garcia BA, Floudas CA. Novel protein identification methods for biomarker discovery via a proteomic analysis of periodontally healthy and diseased gingival crevicular fluid samples. Natl Institutes Heal. 2013;25(3):203-212. 
121. Grover HS, Kapoor S, Saksena N. Periodontal proteomics: wonders never cease! Int J Proteomics. 2013;2013(i):850235.

122. Ata-Ali J, Flichy-Fernández AJ, Alegre-Domingo T, Ata-Ali F, Palacio J, Peñarrocha-Diago M. Clinical, microbiological, and immunological aspects of healthy versus peri-implantitis tissue in full arch reconstruction patients: a prospective cross-sectional study. BMC Oral Health. 2015;15(1):43.

123. Yaghobee S, Khorsand A, Paknejad M. Comparison of interleukin-1 $\beta$ levels in gingival crevicular fluid and peri-implant crevicular fluid and its relationship with clinical indexes. J Dent (Tehran). 2013; 10(1):1-9.

124. Faot F, Nascimento GG, Bielemann AM, Campão TD, Leite FRM, Quirynen M. Can peri-implant crevicular fluid assist in the diagnosis of peri-implantitis? A systematic review and meta-analysis. J Periodontol. 2015;86(5):631-645.

125. Grant MM, Creese AJ, Barr G, et al. Proteomic analysis of a noninvasive human model of acute inflammation and its resolution: the twentyone day gingivitis model. J Proteome Res. 2010;9(9):4732-4744.

126. Basegmez C, Yalcin S, Yalcin F, Ersanli S, Mijiritsky E. Evaluation of periimplant crevicular fluid prostaglandin $\mathrm{e} 2$ and matrix metalloproteinase-8 levels from health to periimplant disease status. Implant Dent. 2012;21(4):306-310.

127. Arakawa H, Uehara J, Hara ES, et al. Matrix metalloproteinase-8 is the major potential collagenase in active peri-implantitis. J Prosthodont Res. 2012;56(4):249-255.

128. Kivelä-Rajamäki M, Maisi P, Srinivas R, et al. Levels and molecular forms of MMP-7 (matrilysin-1) and MMP-8 (collagenase-2) in diseased human peri-implant sulcular fluid. J Periodontal Res. 2003;38(6): 583-590.

129. Gupta A, Govila V, Saini A. Proteomics - the research frontier in periodontics. J Oral Biol Craniofacial Res. 2015;5(1):46-52.

130. Rakic M, Struillou X, Petkovic-Curcin A, et al. Estimation of bone loss biomarkers as a diagnostic tool for peri-implantitis. J Periodontol. 2014;85(11):1566-1574.

131. Wohlfahrt JC, Aass AM, Granfeldt F, Lyngstadaas SP, Reseland JE. Sulcus fluid bone marker levels and the outcome of surgical treatment of peri-implantitis. J Clin Periodontol. 2014;41(4):424-431.

132. Duarte PM, de Mendonça AC, Máximo MBB, Santos VR, Bastos MF, Nociti Júnior FH. Differential cytokine expressions affect the severity of peri-implant disease. Clin Oral Implants Res. 2009;20(5): 514-520.

133. Bordin S, Flemmig TF, Verardi S. Role of fibroblast populations in periimplantitis. Int J Oral Maxillofac Implants. 2009;24(2):197-204.

134. Peker Tekdal G, Bostanci N, Belibasakis GN, Gürkan A. The effect of piezoelectric surgery implant osteotomy on radiological and molecular parameters of peri-implant crestal bone loss: a randomized, controlled, split-mouth trial. Clin Oral Implants Res. 2016;27(5):535-544.

135. Hall J, Pehrson N-G, Ekestubbe A, Jemt T, Friberg B. A controlled, cross-sectional exploratory study on markers for the plasminogen system and inflammation in crevicular fluid samples from healthy, mucositis and peri-implantitis sites. Eur J Oral Implantol. 2015;8(2): 153-166.

136. Flanagan L, Schmid J, Ebert M, et al. Fusobacterium nucleatum associates with stages of colorectal neoplasia development, colorectal cancer and disease outcome. Eur J Clin Microbiol Infect Dis. 2014;33(8): 1381-1390.

Therapeutics and Clinical Risk Management

\section{Publish your work in this journal}

Therapeutics and Clinical Risk Management is an international, peerreviewed journal of clinical therapeutics and risk management, focusing on concise rapid reporting of clinical studies in all therapeutic areas, outcomes, safety, and programs for the effective, safe, and sustained use of medicines. This journal is indexed on PubMed Central, CAS,
137. Ikegami A, Chung P, Han YW. Complementation of the fadA mutation in Fusobacterium nucleatum demonstrates that the surface-exposed adhesin promotes cellular invasion and placental colonization. Infect Immun. 2009;77(7):3075-3079.

138. Liu P, Liu Y, Wang J, Guo Y, Zhang Y, Xiao S. Detection of Fusobacterium nucleatum and fada adhesin gene in patients with orthodontic gingivitis and non-orthodontic periodontal inflammation. PLoS One. 2014;9(1):3-7.

139. Yu F, Iyer D, Anaya C, Lewis JP. Identification and characterization of a cell surface protein of Prevotella intermedia 17 with broadspectrum binding activity for extracellular matrix proteins. Proteomics. 2006;6(22):6023-6032.

140. Laheij AMGA, van Loveren C, Deng D, de Soet JJ. The impact of virulence factors of Porphyromonas gingivalis on wound healing in vitro. J Oral Microbiol. 2015;7:27543.

141. Zhou Y, Sztukowska M, Wang Q, et al. Noncanonical activation of $\beta$-catenin by Porphyromonas gingivalis. Infect Immun. 2015;83(8): 3195-3203.

142. Goulas T, Mizgalska D, Garcia-Ferrer I, et al. Structure and mechanism of a bacterial host-protein citrullinating virulence factor, Porphyromonas gingivalis peptidylarginine deiminase. Sci Rep. 2015;5:11969.

143. Nakayama M, Inoue T, Naito M, Nakayama K, Ohara N. Attenuation of the phosphatidylinositol 3-kinase/Akt signaling pathway by Porphyromonas gingivalis gingipains RgpA, RgpB, and Kgp. J Biol Chem. 2015;290(8):5190-5202.

144. Abiko Y, Nagano K, Yoshida Y, Yoshimura F. Characterization of treponema denticola mutants defective in the major antigenic proteins, Msp and TmpC. PLoS One. 2014;9(11):e113565.

145. Sarkar J, McHardy IH, Simanian EJ, Shi W, Lux R. Transcriptional responses of Treponema denticola to other oral bacterial species. PLoS One. 2014;9(2):1-11.

146. Dashper SG, Seers CA, Tan KH, Reynolds EC. Virulence factors of the oral spirochete Treponema denticola. J Dent Res. 2011;90(6): 691-703.

147. Zhu Y, Dashper SG, Chen YY, Crawford S, Slakeski N, Reynolds EC. Porphyromonas gingivalis and Treponema denticola synergistic polymicrobial biofilm development. PLoS One. 2013;8(8):e71727.

148. Ksiazek M, Mizgalska D, Eick S, Thøgersen IB, Enghild JJ, Potempa J. KLIKK proteases of Tannerella forsythia: putative virulence factors with a unique domain structure. Front Microbiol. 2015; 6(MAR):1-11.

149. Bryzek D, Ksiazek M, Bielecka E, et al. A pathogenic trace of Tannerella forsythia - shedding of soluble fully active tumor necrosis factor $\alpha$ from the macrophage surface by karilysin. Mol Oral Microbiol. 2014;29(6):294-306.

150. Beall CJ, Campbell AG, Dayeh DM, Griffen AL, Podar M, Leys EJ. Single cell genomics of uncultured, health-associated Tannerella BU063 (oral taxon 286) and comparison to the closely related pathogen Tannerella forsythia. PLoS One. 2014;9(2):1-10.

\section{Dovepress}

EMBase, Scopus and the Elsevier Bibliographic databases. The manuscript management system is completely online and includes a very quick and fair peer-review system, which is all easy to use. Visit http://www.dovepress.com/testimonials.php to read real quotes from published authors. 